EPJ Web of Conferences 24, 01001 (2012)

DOI: $10.1051 /$ epjconf/20122401001

(c) Owned by the authors, published by EDP Sciences - SIF, 2012

\title{
Environment protection: The current challenge in radioecology
}

\author{
F. BRÉCHIGNAC*
}

Institute of Radioprotection and Nuclear Safety (IRSN)

General Directorate (DG) and International Union of Radioecology (IUR)

Blg 229, Centre d'Etudes de Cadarache

13115 St Paul-lez-Durance, France

\begin{abstract}
Radioecology, a multifaceted scientific discipline which addresses environmental issues relevant to radioprotection, has for a long time been focused on environmental transfers through the environment to feed the needs of human radioprotection. This quite anthropocentric initial scope is now moving to a more ecocentric view capable of assessing ecological risk mediated by ionising radiation. The central issue consists in reaching an ability to understand the effects of radiation on the environment components, from individual organisms up to populations of species and ecosystems, together with their interaction with the abiotic compartments. Dominated by operational goals, the system of radiological protection of the environment which is under development emphasises a concept based upon reference organisms supported by traditional toxicological data on individual organisms. Whilst there are immediate advantages to this approach (pragmatism, consistency with other approaches in use for man and biota), there are also clear limitations which need to be acknowledged and further considered. The most important probably is to rely on effects data gathered almost exclusively for individual organisms to meet protection goals which are usually set at population and ecosystem levels. Overcoming this limitation leads to scientific and methodological approaches featuring the ecosystem concept.
\end{abstract}

*E-mail: francois.brechignac@irsn.fr

This is an Open Access article distributed under the terms of the Creative Commons Attribution License 2.0, which permits unrestricted use, distribution, and reproduction in any medium, provided the original work is properly cited 


\section{Introduction}

Human health is pledged to the health status of the environment. This is why environmental protection has become an important issue that radiological protection needs to consider. Today, concern exists with respect to the effectiveness of mastering radiological risk in a robust and transparent manner. As a consequence, the International Commission of Radiological Protection (ICRP), which had for a long time simply subordinated environment protection to the protection of human beings, is reconsidering its original paradigm and has initiated the construction of a specific system framework for the radiological protection of the environment (actually protection of non-human biota) against ionizing radiation [1].

Central to the development of this system however still lies an ambiguity as to what "protection of the environment" actually means in terms of its objectives. Indeed, the "environment" notion covers a range of different realities: pristine nature, environmental media such as soils, atmosphere and water (including geological resources, ...), individual organisms of endangered wildlife species, communities of interacting populations of species (fish stocks in the ocean, tropical forest, ...), landscapes, habitats, ecosystems including their provision of life support functions (air regeneration, waste recycling, biomass production ...) and of services (climate control, water regeneration, provision of material and biological resources ...). We stress that the "protection of the environment" terminology is often abusively employed as a generic expression where it actually only addresses a few of the specific aspects mentioned above.

\section{History of environment protection}

Initially, environmental protection was concerned with human health, and the major driver during long periods had been protection of human life per se, without any major need to consider the environment in a broad sense. Much more recently, environmental protection evolved during the $20^{\text {th }}$ century as an issue due to the planetary exponential growth of human population. This population growth, initiated during the $19^{\text {th }}$ century, prompted an associated growth of industrialisation of various processes, including exploitation of natural resources, which have proven to impact on the environment. The goods to humankind provided by these developments, in terms of economical development, have been recognised also to lead to potential deleterious side effects requiring consideration in view of ensuring 


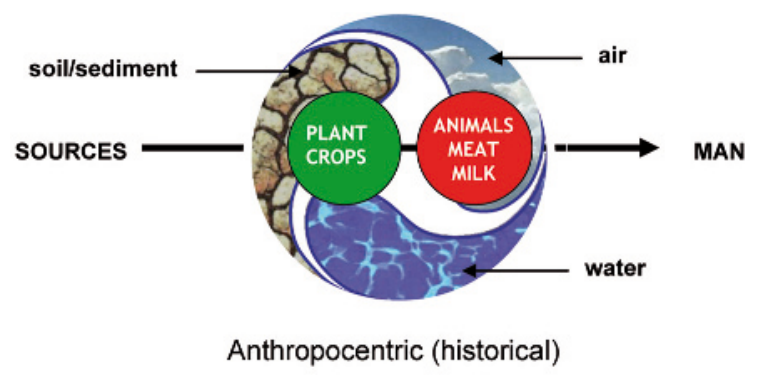

Figure 1: The historical anthropocentric view over the environment for the purpose of its protection against radiation: a linear concept from sources to man.

"sustainability" of the processes concerned. Interestingly, concerns about the environment have not primarily evolved from the harm observed on the environment itself (air, land, water, biota), but rather from the impairments of human health it has been recognised to be able to promote.

In radiation protection, quite similarly, the first phase of development has been anthropocentric (fig. 1), restricting the consideration of the environment to a simple vector of radionuclides to human beings, transferred through air, water, soils and sediments, and/or through animals and plants of agricultural value only (as food source, vegetables, milk, meat, etc ...). Considering human beings as the only target of concern, this phase directly subordinated environment protection to human protection. The resulting concept was therefore quite linear and this feature oriented research work on linear transfer of radionuclides essentially, further considering man as sitting external to the environment.

Probably, the first reason that has driven to protecting the environment per se has been the rarefaction of biological resources (e.g., fish, game, forest) that had been exploited for centuries as granted for free by nature through numerous generations of harvesters, hunters and agriculture growers. This has been followed more recently by facing a rarefaction of species richness (biological diversity, genetic diversity) which in turn promoted societal fears with respect to the sustainability of life and future generations. Next, the growing contamination of these resources by xenobiotics (technogenic substances released by human activities and accumulated in the environment) has been recognised, more or less concomitantly, together with its impact on human health, but also on other life forms. Artificial radionuclides produced within the nuclear cycle of electric power generation, from atomic weapons 
testing or for other industrial and medical purposes, and also "technologically enhanced naturally occurring (radioactive) materials" (TENORMs) resulting from mining and various mineral/organic resources exploitation (oil and gas), all fall in this category.

\section{Biocentric approach based on individual organ- isms}

The growing size of the planetary human population drives to questions relative to the ecosystems' capacity to provide biological resource such as food in a sustainable manner. Ensuring safe food to human populations, is a question of both, the nutritive quality of the biological resources, but also the health status of the corresponding biota from which such food resources are derived, i.e. making sure that the relevant ecosystem processes which provide such resources (so called "services") are not endangered. Indeed, the potential deleterious impacts from xenobiotics introduced into the environment by human (industrial) activities has prompted a concern about the health status of non-human biota, therefore shifting the protection focus from man to other species as well. This is why radiological protection, in a second phase, has moved to a biocentric approach (fig. 2), as currently driven by ICRP Committee 5. Paralleling the system of protection designed for man, it takes now non-human biota as targets of radiation and follows a quite similar conceptual philosophy. The resulting system of protection of "non-human biota" (and not "of the environment", as often abusively stated) is dominated by the need for practical operation, leading in turn to a number of simplifications.

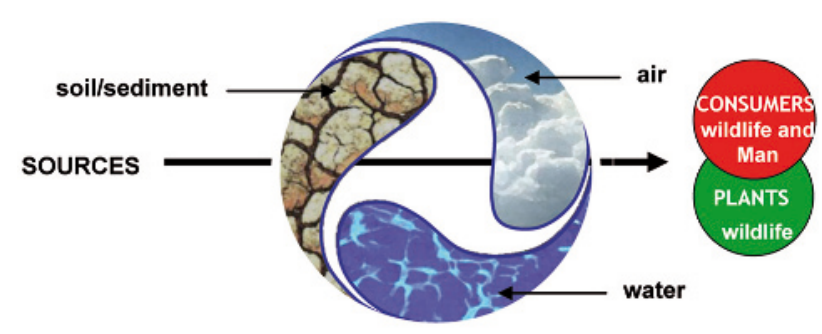

Biocentric (current, ICRP)

Figure 2: The current biocentric view over the environment developed by ICRP for the purpose of its protection against radiation: a linear concept from sources to non-human biota and man. 
One major simplification arising from this concept roots from the problem faced with the vast diversity of species: the system reduces the scope to a small set of "reference organisms" (mimicked from the concept of "reference man" used in human radiation protection), further supported by traditional radio-toxicological data at individual organism level from which typical dose-response curves are derived (from literature knowledge) along four categories of effects endpoints in such individual organisms - mortality, morbidity, reproductive success and mutation - in order to construct a scale of risk [2]. This is still a linear concept, but which emphasizes now effects on non-human biota.

Radiation effects in non-human biota have been subjected to numerous studies in the past decades, but essentially focused upon individual organisms (as for humans) exposed to high levels and acute dose rates of external $\gamma$ irradiation. The resulting overall knowledge therefore still proves to be very fragmented: a poor understanding of the impact of chronic exposures to internally accumulated irradiation in the long run ( $\alpha$ and $\beta$, especially), over several generations of non-human biota, taken as populations of species and their communities. Large gaps also remain with respect to the diversity of animal and plant species. Because these shortcomings are typically overcome by means of extrapolations, also carrying large uncertainties, research work is oriented towards unravelling radiation effects in individual organisms of a larger array of different species exposed to chronic and low dose from internally accumulated radionuclides.

One advantage of this approach is to ensure an immediate consistency with the system of radiological protection of man. This is seducing as it opens the path to designing a unique system of radiological protection of both, humans and "the environment" However, one must strengthen that "the environment" here is actually restricted to "non-human biota" only, taken up to the individual organism level, and not very much more. It is argued here that this is quite a limitation when facing the more holistic nature of environmental problems, as illustrated from: 1) the consensus goal that environment protection needs to be set at the population level (at minimum) or above, 2) the upcoming international legislation which often recommends to adopt an "ecosystem approach", 3) the focus on ecosystemic concepts in other fields of environment protection (biodiversity, halieutics, forestry). 


\section{Justification to emphasizing the ecosystem concept}

Regulatory (and public) perceptions of the value of nature emerge from two major considerations: the need to safeguard biodiversity and the will to preserve life-supporting functions within natural systems such as maintenance of safe drinking water, clean air and safe non-contaminated food, all of which depend on ecosystem level processes.

The need to view environmental problems in a more holistic manner, through the ecosystem concept, comes therefore from the recognition that human health is strongly bound to the health status of the environment itself. Toxic substances which man introduces in the environment elicit direct deleterious effects on humans, animals and plants, but also promote alterations of ecological processes which indirectly impact them, ultimately $[3,4]$. This leads to considering the relationship between environment and human protection no more through a linear view, but as a closed loop within which man promotes changes in the environment (harmful or not to non-human biota), such changes in turn being capable of promoting harmful feed-back impacts in humans. The ecosystem concept best captures this holistic representation of the interactions and relationships between human beings, other species and their environmental surroundings.

\subsection{New ecological theories refer to ecosystems as complex systems}

As a foundation, new ecological/ecosystem theories currently develop a better description and understanding of the behaviour of ecosystems as complex systems [5-7]. As opposed to the classical approach presenting the impacts of toxicants upon various aspects of biological and ecological systems, a new integrated framework is now proposed that incorporates complexity theory.

Essentially, the basic format of this framework features two distinct types of structures which concern risk assessment. Living organisms (left, on fig. 3) have a central core of information, the genome, subject to natural selection, and which drives homeostasis upon the constituents of that system. The genome of an organism is highly redundant, a complete copy existing in virtually every cell, with high communication and coordination between the various constituents within organisms. Somatic cells and structure of the organism are steadily maintained through successive generations by true inheritance through the germ line (unless DNA mutations). Above this individual organism level, ecological (non-organismal) structures have 


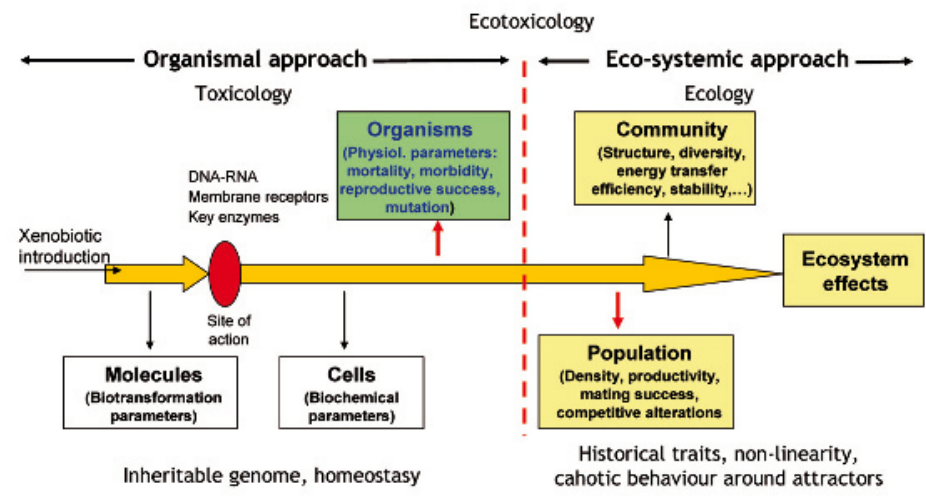

Figure 3: Parameters and indications of the interaction of xenobiotics with all levels of biological organisation within the ecosystem (adapted from [9]).

fundamentally different properties (right, on fig. 3). Here, there is no central and inheritable repository of information, analogous to the genome, which would serve as the blueprint for an ecological system. Natural selection is selfish, working upon the phenotype characteristics of a genome and its close relatives and not upon a structure that exists beyond the confines of a genome. Hence, the lack of a blueprint and the many interactions and nonlinear relationships within an ecosystem mean that the history of past events is written into its structure and dynamics. The many non-linear dynamics and historical nature of ecosystems are characteristic of complex systems, and provide them with emergent properties which are critical to how they react to contaminants.

In this context, Cambel [8] has emphasized the following properties: complex systems are neither completely deterministic or stochastic, they exhibit both characteristics; they undergo irreversible processes; they are dynamic and not in equilibrium, they are constantly moving targets; their different parts are linked and affect one another in a synergistic manner; the causes and effects of the events which the system experiences are not proportional.

\subsection{The goal to protect populations}

Populations form an essential level of interacting components within ecosystems. Population dynamics, in particular, form the minimum inference level allowing to understand the functioning and behaviour of ecosystems. This is why there is a consensus today to consider the population(s) as the most 
relevant and pertinent object of protection and many authors call for ecological risk assessment that would consider risks to populations, no more simply to individual organisms.

It is indeed important to stress that all individual organisms eventually die, whereas populations persist in the long run. As a consequence, interest in population-level ecological risk assessment has dramatically increased within both, the scientific and regulatory communities. SETAC in particular is advancing the practice of population-level ecological risk assessment [9]. Such developments have been prompted by the consensus recognition that individual-based assessments are inadequate for the prediction of the ecological fate of a species-specific endpoint. The current rarity of assessments that focus on population characteristics does not result from the absence of a scientific foundation or understanding, but rather from the lack of concerted effort to advance their use in a risk management context.

An operational definition of the population is essential to examine the biological and ecological context necessary for risk assessments. Roughgarden [10] defined the population as a group of individuals that are genetically and reproductively connected so that the transfer of genetic information to the next generation is greater within the group that between groups. Although the individuals provide the means, reproduction for obligate sexual organisms is a population-level property. A ramification of this definition is that the individual organism is ecologically insignificant unless placed in the context of a population. The population provides the individual mates, a gene pool for genetic recombination, social structure, modified habitat, and all other information necessary for the survival and transmission of the genetic information of the individuals to the next generation.

\subsection{The subsystems-to-system extrapolation in question}

Controlled laboratory tests on single-species systems provide clear and easily understood linkages between stressor exposure and effects. They are typically inexpensive, quick and easy. But a population perspective invites examination of complexity and the use of experimental information to address issues associated with multiple stressors, cumulative effects and realworld population dynamics. Factors regulating populations such as disease, predation, and combination of stressors are important to consider. Criticisms of the extrapolation from laboratory single-species toxicity tests to an ecosystem effects approach state that toxicity tests do not consider bioaccumulation of contaminants and ignore both temporal changes and multiple stressors effects. 
Indeed, recent observations or experimental investigations on the effects of radiation have demonstrated that overall responses at ecosystemic level may not be simply derived from local responses observed at individual organism level [11]. This can be due to indirect effects mediated through alteration of trophic interactions between populations of different species [12,13]. But more generally, this roots from "emergent" properties of ecosystems, like resilience or resistance, which drive to non straightforward propagation of effects across levels of biological organisation [14], or through successive generations $[15,16]$. Similar responses have already been faced in other fields of environmental protection against other stressors, pushing a number of environment professionals to assign stronger emphasis on more systemic approaches.

\subsection{The resilience/resistance of ecosystems in the face of stress}

Resilience and resistance are specific properties of ecosystems emerging from complexity, both referring to their stability. Resistance is defined as the capacity of a community to maintain its structure following exposure to perturbation (that is to absorb disturbance), and resilience the capacity of the ecosystem to reorganise while undergoing change so as to retain essentially the same function, structure, identity and feedbacks (ecological resilience, after Folke et al. [17]).

When exposed to gradual changes in biotic and/or abiotic factors, ecosystems usually respond to these perturbations in a smooth way or even without any externally visible response. However, in some occasions, sudden catastrophic shifts between different ecosystem states, which are called "regime shifts" around "attractors", are observed to occur. These are caused by the combination of the magnitudes of external forces (the above-mentioned changing factors) and the internal resilience of the system. As anthropogenic disturbance (pollutant) or natural factors increase (i.e. nutrient loading, climate and habitat fragmentation), the ecosystem, becoming vulnerable to smaller disturbances or gradually changing conditions that it could previously cope with, is now at high risk of shifting to a qualitatively different state. Such shifts may be difficult or impossible to reverse.

A quite commonly described example of such "catastrophic regimes" is the eutrophication observed in lakes responding to nutrient loads, an explanation of which is summarized by Bréchignac [3]. The pristine status of most shallow lakes is clear water with rich submerged bottom vegetation. After a certain degree of nutrient accumulation, the lake shifts abruptly 


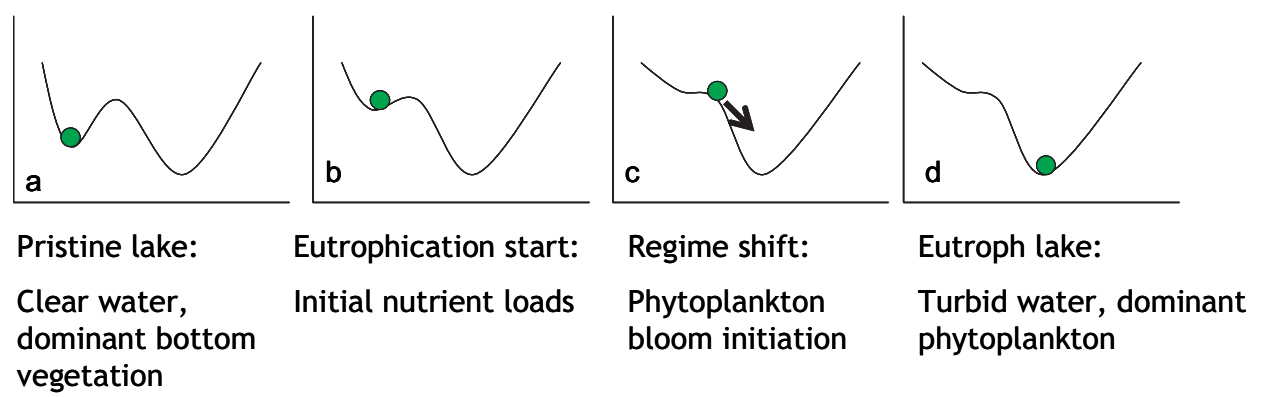

Figure 4: Regime shift of an ecosystem as resulting from its resilience decrease (adapted from [17]).

from clear to turbid with high levels of phytoplankton and loss of bottom vegetation (fig. 4). The original status may eventually be reversed, but only after dramatic reduction of nutrients, down to much lower than the level at which the regime shift occurred (high hysteresis).

One understands from this feature of ecosystems that depending on the status of their intrinsic level of resilience/resistance, their radio-sensitivity may be quite different, absorbing radiation stress when there are resilient/resistant, or eventually undergoing catastrophic shift when their resilience/resistance is altered (by previous continuous exposure to stress, for example).

\section{The emergence of the "ecosystem approach" concept}

The above-mentioned considerations lead to advocating the need to boost science and methods along an ecocentric approach $[3,4,18]$, in a third phase (fig. 5). Leaving the previous linear view, the approach features now the ecosystem, with its loops of material and energy cycling, as a central concept to structure the system of radiological protection (of the environment, including man).

There is indeed a growing awareness nowadays among policy makers and scientists that assessment studies should adopt an ecosystem approach. Started almost two decades ago, this trend is best illustrated by the vast literature on this subject area [19], demonstrating that environmental managers, the primary customers of methodologies for ecological risk assessment, have shifted towards applying an ecosystem approach to environment management. 


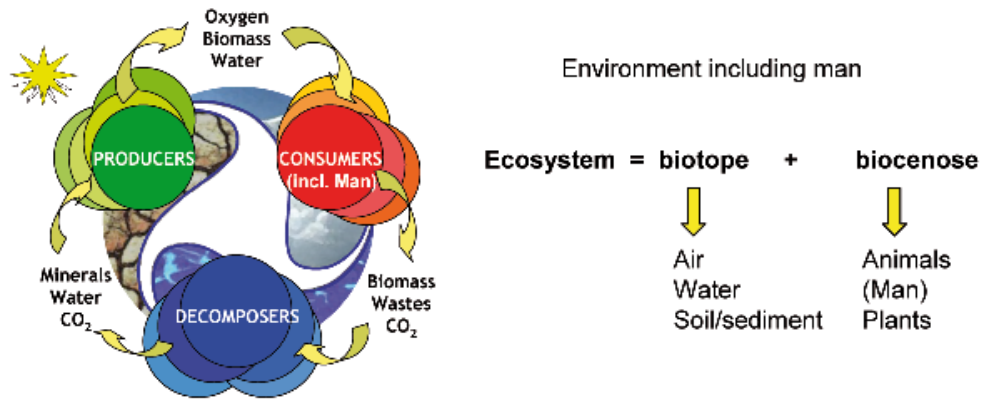

Ecosystem services : waste recycling, provision of material ressources, climate regulation, ...

Ecosystem life support : air bioregeneration, water recycling, biomass (food) production,...

Figure 5: Ecocentric approach for environment protection featuring the ecosystem concept, with loops of material and energy transformation (action and feed-back). Man is located within the ecosystem, as part of the consumers' functional group.

Today, the recommendation to apply an ecosystem approach can be traced within many governmental institutions and agencies throughout the world, as related to the protection of biodiversity [20], of marine resources [21], of marine and coastal environments [22], among many others.

\section{Conclusion}

There are several advantages expanding the system of radiological protection of the environment to considering an ecosystem approach. First, it overcomes the large uncertainties generated by the otherwise necessary extrapolations from organism toxicology to impacts on ecosystems. Second, it solves the ambiguity stressed above with respect to the "environment" terminology because it embraces an overarching goal of protection: preserving life sustainability through protection of ecosystem structure and functioning. Finally, it improves the radiological protection credibility by adopting the modern concepts which the overall environment protection community is now developing to overcome and prevent man-made damages to the ecosystem-based sustainability of life.

A potential definition for the "ecosystem approach" proposed here in the context of environment protection against radiation is attempted below.

The ecosystem approach for assessment of environment protection against radiation is a holistic strategy for risk characterisation which integrates the radio-toxicological knowledge together with the ecological 
understanding within an ecosystem-centered conceptual view. The ecosystem concept is stressed and acknowledged for several reasons:

- it best integrates the general objectives of environment protection, which overall refer to ecosystem structure (biodiversity) and functions (ecosystem services);

- it aims at balancing the use of both, reductionist micro-explanationbased methods providing inference to mechanisms (toxicology, bottomup) and integrated macro-explanation-based methods providing inference to the real nature (ecology, population dynamics, top-down);

- it therefore aims at filling the gap between current methods exclusively relying on organism level radiotoxicology and such general objectives of environment protection;

- it finally meets the end users strategy currently developed for management purposes.

The sustainability of life (the actual main driver for environment protection, including man), is not exclusively a question of toxicological harm to organisms, but also a question of maintaining symbiotic-like assemblies of interacting species in ecosystems because these latter provide essential features such as life support and many services. In other words, life sustainability is best characterized in terms of ecosystems which include organisms rather than in terms of individual organisms only. However, resilience, resistance and non-linear responses to impacts are key ecosystem attributes needing further consideration in this context.

\section{Acknowledgements}

This brief presentation of the "ecosystem approach" recommended to upgrade the upcoming system for the radiological protection of the environment is currently being elaborated in more details by a multidisciplinary expert group gathered under the auspices of the International Union of Radioecology (IUR, www.iur-uir.org). It is therefore a duty for the author, also the initiator of this Task group, to acknowledge the on-going contributions from all members of the group in advance to the publication of their work within the IUR Report series foreseen in 2012. At the time of writing this overview, the task group was composed of: Lawrence Barnthouse, 
Clare Bradshaw, Simon Carroll, Shoichi Fuma, Lars Hakanson, Alicja Jaworska, Lawrence Kapustka, Isao Kawaguchi, Alexander Kryshev, Deborah Oughton, Luigi Monte, Tatiana Sazykina and Per Strand.

\section{References}

[1] ICRP Protection of Non-human Species from Ionising Radiation. Proposal for a Framework for the assessment of ionising radiation in the environment. Annals of the ICRP, Publication 91 Pergamon Press, Oxford, UK (2003).

[2] ICRP Environmental protection: the concept and use of reference animals and plants. Annals of ICRP, Publication 108 Elsevier, Amsterdam, The Netherlands (2008); 242 pages.

[3] BréChignac F. Protection of the environment: how to position radioprotection in an ecological risk assessment perspective. The Science of the Total Environment, 307 (2003); 37-54.

[4] Bréchignac F., Doi M. Challenging the current strategy of radiological protection of the environment: arguments for an ecosystem approach. J. Environ. Radioact. 100 (2009); 1125-1134.

[5] Jørgensen S. E. Towards a thermodynamics of biological systems. Int. J. Ecodyn. 1 (2006); 9-27.

[6] KAY J. J. Ecosystems as self-organising holarchic open systems: narratives and the second law of thermodynamics. In: Handbook of ecosystem theories and management, edited by Joergensen S. E., Müller F. CRC Press, Lewis Publishers (2000); pp. 135-160.

[7] Müller F., Hoffmann-Kroll R., Wiggering H. Indicating ecosystem integrity - Theoretical concepts and environmental requirements. Ecological Modelling 130 (2000); 13-23.

[8] Cambel A. B. Applied chaos theory: A paradigm for complexity. Academic press, Inc., Boston, MA, USA (1993).

[9] Landis W., Yu M-H. Introduction to environmental Toxicology - Impacts of chemicals upon ecological systems Lewis Publishers, CRC Press, Boca Raton, London, New York, Washington D.C. (2004); 484 pages. 
[10] Barnthouse L. W., Munns W. R., Sorensen M. T. Populationlevel Ecological Risk Assessment. Society of Environmental Toxicity and Chemistry, CRC Press (2007); 337 pages.

[11] Roughgarden J. Theory of population genetics and evolutionary ecology: an introduction Prentice-Hall Inc., Upper Saddle River, NJ, USA (1996).

[12] Bothwell M. L., Sherbot D. M. J., Pollock C. M. Ecosystem response to solar ultraviolet-B radiation: Influence of trophic-level interactions. Science 265 (1994); 97-100.

[13] Fuma S., Ishit N., Takeda H., Miyamoto K., Yanagisawa K., Ishimasa Y.,Saito M., Kawabata Z., Polikarpov G. G. Ecological effects of various toxic agents on the aquatic microcosm in comparison with acute ionising radiation. J. Environ. Radioact. 67 (2003); $1-14$.

[14] Doi M., Kawagushi I., Tanaka N., Fuma S., Ishir N., Miyamoto K., Takeda H., Kawabata Z. Model ecosystem approach to estimate community level effects of radiation. Radioprot. Suppl. 1, 40 (2005); S913-S919.

[15] Sokolov V. E., Krivolutsky D. A. Change in ecology and biodiversity after a nuclear disaster in the southern Urals. Pensoft Publishers, Sofia, Moscow (1998); 228 pages.

[16] Massarin S., Alonzo F., Garcia-Sanchez L., Gilbin R., Garnier-Laplace J., Poggiale J. C. Effects of chronic uranium exposure on life history and physiology of Daphnia magna over three successive generations. Aquatic Toxicology 99 (2010); 309-319.

[17] Folke C., Carpenter S., Walker B., Scheffer M., Elmquist T., Gunderson L., Holling C. S. Regime shifts, resilience, and biodiversity in ecosystem management. Annu. Rev. Ecol. Evol. Syst. 35 (2004); 557-581.

[18] BRÉCHIGNAC F. Environment versus man radioprotection: the need for a new conceptual approach ? Radioprotection 37-C1 (2002); 161-166.

[19] Crober A. An annotated bibliography on the ecosystem approach to ecosystem management. Senior Honous Thesis, Department of Geography, Faculty of Environmental Studies, University of Waterloo, Canada 
(1999). Available from: http://www.nesh.ca/jameskay/ersserver. uwaterloo.ca/jjkay/.

[20] Convention on Biological Diversity. Ecosystem approach (2004) COP 5 Decision $\mathrm{V} / 6$.

[21] FAO Food and Agriculture Organisation. Fisheries management. 2. The ecosystem approach to fisheries FAO Fisheries Technical Guidelines $\mathrm{n}^{\circ}$ 4, Suppl. 2 (2005).

[22] Laffoley D. D’A., Maltby E., Vincent M. A., Mee L., Dunn E., Gilliland P., Mortimeer D., Pound D. The ecosystem approach. Coherent actions for marine and coastal environments. A report to the UK Government. English Nature, Peterborough (2004); 65 pages. 